\title{
A STUDY OF THE SUPRACONDYLOID PROCESS IN THE
} LIVING

\author{
R. J. TERRY \\ Washington University, St. Louis
}

The literature of variation in man forms a considerable proportion of the writings in anatomy. It is a record mainly of observations made from dissections or upon the skeleton-that is to say upon the dead remains. The period during which the records have been taken is long enough to prove that all of the more usual and obvious variations have been revealed and described in greater or less detail. Very little is known, however, about the inheritance of the long list of variations encountered in the cadavers of the dissecting laboratory. It is apparent that the examination of this dead material (bodies of persons whose family connections are unknown) is not favorable in certain respects for the pursuit of studies of inheritance. If such inquiries are to be made, some other method must be devised.

The study of the anatomy of the living is a means of approaching a solution of the problem which promises reward. Variation of superficial muscles can be observed by inspection, and many anomalies of the skeleton can be discovered by palpation. The X-ray is daily revealing to the diagnostician unexpected deviations from the normal, some of which already have aroused the suspicion of being family. traits. The advantage to be derived from studying variation in a living man over that of dead material scarcely calls for mention. The objective observation which in the cadaver is limited to the form location, dimension, spatial relationship and morphological correlation of the anomaly is extended in the living into the domain of function. The individual habits may be observed. Furthermore, a subjective examination may be looked to to make known a class of phenomena that are correlated with the presence of a given variation. We already have knowledge of this sort.

The first consideration before adopting a new method should be a test of its usefulness. We have attempted in this paper to describe

Amer. Jovr. Phys. Anthrop., Vol. IV, No. II 
our method of examining the living for the supracondyloid process and to show to what extent it may be relied upon to yield trustworthy results. As a criterion for the test, the incidence, upon which there are available figures, has been chosen.

The present work was undertaken in 1920. Materials for study were sought for in the Dispensary of the Washington University School of Medicine. By cooperation of the Dispensary Committet and staff an examining room was provided and arrangements made by which all the patients to the Dispensary presented themselves for observation. Exceptions were made in the case of infants and of adults whose condition was unfavorable for the examination. One thousand and forty persons were seen; the forty over the thousand were added to replace a like number rejected in the course of the examination because, on account of excessive fleshiness or muscularity, it was impossible to be certain of the presence or absence of the variation. Dispensary patients at random came to our examining room after having been registered at the office and assigned prov1sionally to a service of the clinic. The group represented the poorer element of the population of St. Louis and its suburbs. Provision was made against the possibility of examining by mistake the same patient more than once.

Method of examining. The examiner, seated, placed the subject, arms bared, before him and palpated in turn the left and right arm with the fingers of his right and left hands. The wrist of the subject was held by the opposite hand of the examiner and slow passive motion of the elbow was produced in order to bring about complete relaxation of the muscles of the arm. The anterior aspect of the lower one-fourth of the humerus and medial epicondylar ridge were explored in every case where this was possible. Cases were rejected when excessive fat, tense muscles or fascia interfered. When a supracondyloid process was discovered or suspected the arm was x-rayed. Sometimes three exposures were necessary to reveal the process. The plates were all made in contact with the arm and consequently little distortion resulted in the picture. The measurements of the process were made on the plates by calipers. The height of the process is its greatest projection away from the shaft of the humerus. Distance of the process above the trochlea was measured from the lowest point of the trochlea to the lower margin of the base of the process. All the processes observed were spine-formed, either moderately curved 
or slightly hooked. The terms anterior, medial and intermediate refer to the position of the origin of the process from the shaft of the humerus, eg., near the anterior margin, near the medial epicondylar ridge or between these points from the antero-medial surface of the bone. A few measurements and other anthropological data of the subjects having the variation were taken in order to keep before us a picture for reference and memoranda for future use. Relative strength of pronation and supination was determined by a simple torsion spring device which the subject operated and which gave direct readings, not however sufficiently accurate to be of scientific use. The results obtained are only suggestive. This question will be carefully tested in future examinations. Materials for the study of inheritance presented themselves definitely in at least one of the families examined; the search for living relatives of all of our cases is in progress. On aecount of the claim of association of this variation with mental defect made by previous observers, the diagnosis of our patients was determined and inquiry and record made as to the presence or absence of mental disease in the family.

The following table represents the character of the material studied:

TABIE I.

\begin{tabular}{l|l|c|c|c}
\hline \hline & Males & Female & Totals \\
\hline White & $\begin{array}{l}\text { 21 yrs. and } \\
\text { over }\end{array}$ & 244 & 271 & 515 \\
\hline $\begin{array}{l}\text { Under 21 } \\
\text { Colored }\end{array}$ & 71 & 97 & 168 \\
\hline $\begin{array}{l}21 \text { yrs. and } \\
\text { over }\end{array}$ & 102 & 146 & 248 \\
\hline Totals & 18 & 51 & 69 \\
\hline
\end{tabular}

DESCRIPTION OF CASES

Observation 1. Feb. 25, Dispensary No. A31838. Male; white; 65 yra.; wt., $62.7 \mathrm{~kg}$.; height standing $167.5 \mathrm{~cm}$.; arm length (r.) 72.5 cm., (1.) $73.5 \mathrm{~cm}$., forearm length (r.) $24.5 \mathrm{~cm}$., (1.) $25 \mathrm{~cm}$., span 169.5 $\mathrm{cm}$; head length $19.2 \mathrm{~cm}$., breadth $156 \mathrm{~cm}$., cephalic index 81.25 . 
Hair-color, light brown; eye-color, light blue. Supracondyloid process, left (fig. 1) ; form, curved; position intermediate; $8.3 \mathrm{~cm}$. abovt trochlea; height $3.5+\mathrm{mm}$.; A large nerve (median?) lies behind process; a large superficial artery (brachial?) in front of process. Strength of pronation $r .>1$. The palmaris longus muscle is absent on the left side. Subject unmarried, parents dead; one sister and one step-sister living. Occupation, iron worker. Diagnosis syphilis.

Observation II. Feb. 25. Dispensary No. A33295. Male; white; 20 yrs.; laborer. Assigned to rhino-laryngology. Small supracondyloid process on left side. No further observations possible up to the time of writing.

Observation III. Feb. 28. Dispensary No. A34175. Female, white; 36 yrs.; wt., $58.07 \mathrm{~kg}$; height standing, $167.2 \mathrm{~cm}$.; arm length (r) $79.8 \mathrm{~cm}$., (1.) $78.6 \mathrm{~cm}$; forearm length, (r.) $27 \mathrm{~cm}$., (1.) $26 \mathrm{~cm}$., head length $17.8 \mathrm{~cm}$; breadth $14.9 \mathrm{~cm}$.; cephalic index 82.0; hair color, dark brown; eye color, blue with brown spots; supracondyloid process, left (fig. 2); form, curved; position, anterior; $6.6 \mathrm{~cm}$. above trochlea; height $7+\mathrm{mm}$.; pulse at process; nerve back of process. Palmaris longus absent, left. Subject married, but separated from husband; father dead, mother living; brothers and sisters living. Occupation, laundress; diagnosis, pulmonary tuberculosis; no family history of nervous diseases.

Observation IV. Mar. 2. Dispensary No. A34232. Male; colored; 42 yrs.; wt., $70.23 \mathrm{~kg}$; height standing, $172 \mathrm{~cm}$; arm length (r.) $77.5 \mathrm{~cm}$., (1.) $76.8 \mathrm{~cm}$; forearm length (r.) $27 \mathrm{~cm}$., (l.) $27 \mathrm{~cm}$. head length $20.0 \mathrm{~cm}$., breadth $15.2 \mathrm{~cm}$., cephalic index, 76. Hair color, dark brown; eye color, dark brown; supracondyloid process bilateral (fig. 3, 3a) ; form, curved; position intermediate; right, $78 \mathrm{~cm}$., left, $8.4 \mathrm{~cm}$. above trochlea; height (r.) $4+\mathrm{mm}$.; (l.) $4+\mathrm{mm}$.; pulse at process. Nerve behind process. Strength of pronation $r .>1$. Palmarls longus muscle present on both sides. Subject married, no children; parents dead; 2 brothers living, married; 2 sisters, 1 living and married, other dead. Occupation, laborer. Diagnosis syphilis.

Observation V. Mar. 2. Dispensary No. A17146. Female; white; 30 yrs.; wt. $50.7 \mathrm{~kg}$; height standing $169 \mathrm{~cm}$.; arm length (r.) 73 cm., (l.) $72 \mathrm{~cm}$.; forearm length (r.) $25 \mathrm{~cm}$.; (1.) $25 \mathrm{~cm}$; span 169.5 $\mathrm{cm}$; head length $18 \mathrm{~cm}$., breadth $14.3 \mathrm{~cm}$; cephalic index 79.4; hair color, dark brown; eye color, blue; supracondyloid process left (fig. 4); form, hooked; position anterior; $7.7 \mathrm{~cm}$. above trochlea; height 
$6.5+\mathrm{mm}$.; pulse and nerve at process; strength pronation $1 .>$ r. X-ray reveals two osseous nodules just inferior to medial epicondyle (fig. 5). Subject married, not living with husband; no children. Parents both living; no evidence of supracondyloid process; 2 paternal aunts dead; 2 maternal aunts living; one examined for process, negative; subject has 4 brothers, all living; one possesses supracondyloid process, bilaterally. X-ray reveals nodule of bone adjacent to tip of medial epıcondyle (epiphysis?) (fig. 6) ; other brothers negative; 2 sisters, one unmarried has supracondyloid process on right (table V); married sister's 2 children, negative; 4 miscarriages in subject's generation. Occupation, housewife. Diagnosis pelvic cellulitis, psychoneurosis.

Observation VI. Mar. 3. Dispensary No. A33076. Male; white, 33 yrs.; wt. $63.2 \mathrm{~kg}$.; height standing $166.4 \mathrm{~cm}$.; arm length (r.) 75.5 cm.; (1.) $74.5 \mathrm{~cm}$.; forearm length (г.) $25 \mathrm{~cm}$., (1.) $25 \mathrm{~cm}$; head length $19.5 \mathrm{~cm}$., breadth $15.4 \mathrm{~cm}$; cephalic index 79.0; hair color, dark brown; eye color, brown; supracondyloid process left (fig. 7); form, curved; position medial; $8 \mathrm{~cm}$. above trochlea; height $5.5+\mathrm{mm}$.; pulse and nerve at process. Palmaris longus well developed. Subject's mother dead, 67 yrs.; father living, negative; 4 brothers, all dead; 3 sisters, 1 unmarried, 2 married, all negative; daughter 9 yrs. of ont sister negative. Occupation, laborer; diagnosis rectal fistula; no nervous disorder in family.

Observation VII. Mar. 16. Dispensary No. A34938. Female;

TABLE II.

(Seven individuals presenting the supracondyloid process variation in 1,000 living subjects.)

\begin{tabular}{|c|c|c|c|c|c|c|c|}
\hline Observ. & Sex & Color & Left & Right & $\begin{array}{c}\text { Form of } \\
\text { Spine }\end{array}$ & $\begin{array}{c}\text { Height } \\
(\mathrm{mm} .)\end{array}$ & $\begin{array}{c}\text { Age } \\
\text { Years }\end{array}$ \\
\hline 1. & $\mathbf{M}$ & $W$ & + & 0 & curved & $3.5+$ & 65 \\
\hline II. & $\mathbf{M}$ & W & + & 0 & $?$ & $?$ & 20 \\
\hline III & F & W & + & $\mathrm{O}$ & curved & $7+$ & 36 \\
\hline IV & $\mathbf{M}$ & C & + & + & curved & $\begin{array}{l}\text { r. } 4+ \\
\text { 1. } 4+\end{array}$ & 42 \\
\hline V. & $\mathbf{F}$ & W & + & 0 & hooked & 6.5 & 30 \\
\hline VI. & $\mathbf{M}$ & W & + & 0 & curved & 5.5 & 33 \\
\hline VII. & $F$ & W & 0 & + & curved & $72+$ & 41 \\
\hline
\end{tabular}


white; 41 years; wt. $58.4 \mathrm{~kg}$; height standing $164.7 \mathrm{~cm}$., arm length (r.) $75.6 \mathrm{~cm}$., (l.) $74.6 \mathrm{~cm}$; forearm length (r.) $24.0 \mathrm{~cm}$., (l.) 25.3 $\mathrm{cm}$; hair color, light brown; eye color, blue with brown spots; supracondyloid process right (fig. 8) ; form, curved; position intermediate; $7.8 \mathrm{~cm}$. above trochlea; height $7.2+\mathrm{mm}$.; Subject widow; parents dead; 1 brother and 1 sister living (not examined); 1 son, negative. Occupation, housewife. Referred to neurological clinic; no family history of nervous disease.

\section{INCIDENCE}

In 1889 Testut $^{1}$ published the results of his studies on the supracondyloid process in man which included the question of its incidence. He proved that in the group examined the occurrence of the process was not so frequent as had been found by the two earlier investigators of the subject, namely, Struthers and Gruber. Since the appearance of Testut's work, reports have been made, indicating a considerably higher incidence in special groups, viz., among the insane and in criminals as stated above.

\section{TABLE III.}

Testut's eight individuals presenting the supracondyloid process variation in 929 cadavers.

\begin{tabular}{|c|c|c|c|c|c|c|}
\hline Observ. & Sex & Left & Right & $\begin{array}{l}\text { Length } \\
(\mathrm{mm} .)\end{array}$ & Age & Form \\
\hline $\mathrm{XV}$. & M & + & & 18 & spine & adult \\
\hline XVI. & M & & + & & tubercle & adult \\
\hline XVII. & & + & + & $\begin{array}{c}\text { r. } 7 \\
\text { 1. well de- } \\
\text { veloped }\end{array}$ & $\begin{array}{l}\text { r. triang. } \\
\text { l. ? }\end{array}$ & 13 yrs. \\
\hline XVIII. & F & 0 & + & & spine & $11 \mathrm{yrs}$. \\
\hline XIX. & M & & + & $2-3$ & rounded & \\
\hline $\mathrm{XX}$. & M & + & & 8 & spine & $50-55$ yrs. \\
\hline XXI. & M & 0 & + & 4 & $\begin{array}{l}\text { cartilag. } \\
\text { tubercle }\end{array}$ & 35 yrs. \\
\hline XXII. & $\mathbf{F}$ & + & O & 5 & triang. & adult \\
\hline
\end{tabular}

1Testut (L.)-L'Apophyse sus-epitrochléene chez l'homme. Internat. Monatschr. f. Anat, u. Physiol., 1889, VI. 
Struthers ${ }^{2}$ gives the incidence at $2 \%$. He says, "As to the frequency of its occurrence in the human body, I have been in the habit of estimating that it may be found present, as more or less of a process, in about one in fifty, but not so often in its complete state as a long spur-like process." On the authority of Testut ${ }^{1}$, Gruber found the incidence to be $2.7 \%$. Gruber's monograph ${ }^{3}$ describes minutely his observations on the cadaver, but it is not clear to me how the inc1dence was computed. The conditions under which Testut's figure have been reached are recorded in his work published in 1889. This author examined in his laboratory at Lyon (1886-1888) 719 cadavers and found the apophysis seven times; (1888-89) 210 cadavers and two processes (Tab. III).

The figures of Nicholas ${ }^{4}$ for the insane and of Valenti ${ }^{5}$ for crimTABLE IV.

Hrdlicka's classification and summary of the incidence of the supracondyloid process in 1309 humeri (654 right; 655 left) of adult whites from the dissecting laboratory of the College of Physicians and Surgeons, New York (1892-1910):

Location $=2.7$ to $4.5 \mathrm{~cm}$. above upper border of anterior fossa.

\begin{tabular}{|c|c|c|}
\hline No trace of process in $\ldots \ldots \ldots \ldots \ldots \ldots, 552=42 \%$ & $(42.17)$ & $\left\{\begin{array}{l}289 \mathrm{r} . \\
263 \mathrm{l} .\end{array}\right.$ \\
\hline Moderate roughness in its place $\ldots \ldots \ldots .276=21 \%$ & $(21,09)$ & $\left\{\begin{array}{l}130 \mathrm{r} . \\
146 \mathrm{l} .\end{array}\right.$ \\
\hline Pronounced roughness in its place......... & $(0.31)$ & $\left\{\begin{array}{l}3 \mathrm{r} . \\
1 \mathrm{l} .\end{array}\right.$ \\
\hline $232=18 \%$ & $(17.72)$ & $\left\{\begin{array}{r}98 \mathrm{r} . \\
134 \mathrm{l} .\end{array}\right.$ \\
\hline Pronounced ridge in its place $\ldots \ldots \ldots \ldots, 107=8 \%$ & $(7,72)$ & $\left\{\begin{array}{l}53 \mathrm{r} . \\
54 \mathrm{l} .\end{array}\right.$ \\
\hline Small tubercle..... & $(3.82)$ & $\left\{\begin{array}{l}29 \mathrm{r} . \\
21 \mathrm{l} .\end{array}\right.$ \\
\hline Pronounced tubercle in its place.......... & $(1.53)$ & $\left\{\begin{array}{r}12 \mathrm{r} . \\
81 .\end{array}\right.$ \\
\hline Process $(0.3$ to $0.9 \mathrm{~cm} . \mathrm{high}) \ldots \ldots \ldots \ldots$ & $(1.07)$ & $\left\{\begin{array}{r}11 \mathrm{r} . \\
31\end{array}\right.$ \\
\hline
\end{tabular}

2Struthers (J.) - On the processus supracondyloideus humeri of Man. Trans. Internat. Med. Cong., Lond., 1884.

${ }^{3}$ Gruber (W.)-Monographie des Canalis supracondyloideus humeri. Mem. Acad. Sci., St. Petersbourg, 1859, III.

${ }^{4}$ NicoLAs (A.)-Nouvelles observations d'apophyse sus-epitrochléene chez l'homme. Rev. Biol. du Nord de la France, 1890-91, JII.

5VALENti $(G)$. Processo sopracondiloideo dell' omero in due crimunali ed in una pazza. Atti e Rendic. Accad. med.-chir. Perugia, 1896, VIII. 
inals will not be discussed in this paper since they are concerned with the correlation of the variation in special groups.

A careful analysis of the occurrence of the supracondyloid process in man has been made by Hrdlička who has generously given me his unpublished results for study and comparison (Tab. IV).

As a basis for comparison of results of studies of incidence it is obvious that there should be agreement upon what constitutes a supracondyloid process and an understanding of the method used in makıng the calculation for incidence.

Struthers first drew attention to the common occurrence in humen of a ridge or line at the site where the supracondyloid process presents itself. The reasons for regarding such ridges as supracondyloid process in nature are well known. Koughness at the site has alsu been accepted as evidence of the variation in question; it may exist alone and independent of a superimposed process or, as Testut found in one case, it may be the seat of articulation with a cartilaginous tubercle. Such a cartilaginous supracondyloid process, easily palpable, but not shown by X-ray, was found in a boy of 19 years in connection with, but not included in, the present investigation. The tubercle is also a form taken by this variation. Still another form is the triangular process, which appears to be a short spine surmounting a broad compressed base. It is necessary to the securing of reliable results that the different forms and degrees of development taken by the variation should be distinguished. The classification adopted by Hrdlička satisfies this need.

The combination of dissection and preparation of the skeleton ought to yield all data necessary for the proper identification of the variation, its form, position and degree of development. However, unless there be continuous supervision and scrutiny of the work of the students in the dissecting room the smaller processes, ridges and rough spots will pass unobserved, and would only be discovered in the examination of the prepared skeletons. Examination of the skeleton alone is sufficient for determining the incidence providing of course that the material is authenticated as to sex, race, age and symmetry. It must be remembered, however, that the occurrence of a cartilaginous process would be missed in the ordinary methods of macerating the arm bones, and that the lack of evidence given by the soft parts may leave the nature of the less typical forms of variation at the site in some doubt as to their true nature. Calculation of the 
incidence by examining the arms in the living has proved to be reliable so far as the detection of a true process is concerned; however, processes less than $4 \mathrm{~mm}$. in height, tubercles, rough places and ridges were only exceptionally discovered by palpation in our experience, and because of uncertainty as to their relation to the supracondyloid variation have not been recorded or otherwise included in this work.

In our 1000 dispensary patients, 7 individuals presented a supracondyloid process in the form of a spine, easily discovered by palpation and revealed by the X-ray. The incidence under the conditions of race, age and sex shown in tables $I$ and II, of persons presenting spinous formed supracondyloid processes is $0.7 \%$. Testut derives his figure $(1 \%)$ on the occurrence of 9 apophyses in 929 subjects (table III). There were 8 individuals in the total number presenting the variation, an incidence on this basis of $.8 \%(0.861)$. Eliminating the two cases presenting tubercles, the figure falls to $.6 \%(0.645)$, a little less than our result which does not include the tubercular form of the process.

As there were 237 individuals under 21 years of age in our series of 1000 and none presented a palpable supracondyloid process, the incidence of individuals having the process among the total number of adults will be $.9 \%(0.92)$. I do not attach much importance to this figure since it is well known that the process occurs in children. I have seen one well marked spine in the humerus of a new born child. The percentage is stated because most of the studies of the process have been upon the adult bodies of the dissecting room. The total number of adults was 763 of which 520 were white, 243 colored.

Of the 6 individuals having the variation, one was a negro; therefore somewhat over $1 \%$ (1.15) of the adult whites presented the process. The total number of negroes examined (only 243) is too small for obtaining trustworthy percentages. The presence of the variation, bilaterally, in the negro should not be accepted as proof of the occurrence, even rarely, of the supracondyloid in that race. In this instance there is some evidence of admixture of white ancestry in the family.

Regarding the incidence of processes in the total number of arms examined; this was 8 in 1526 , or $.5 \%(0.524)$. As to the number of processes in the humeri of adult whites there were found 6 in 1040, or somewhat less than $.6 \%(0.58)$. This is a lower incidence than that given by Hrdlička (1.07). Some part of the discrepancy between these percentages can be accounted for by the fact that our observa- 
tions do not include any spur under $4 \mathrm{~mm}$. in height. Collections of humeri show that processes under $4 \mathrm{~mm}$. are not rare. It is to be assumed that such small elevations were present in our group but failed of detection by palpation.

Table II represents the distribution of the supracondyloid process in respect to sex, age and symmetry in the 7 individuals in our series having the variation. What the mode of distribution may be as influenced by these factors, must await a large collection of material presenting the variation.

The Supracondyloid Process in the Family of A. 17146. Observation V.

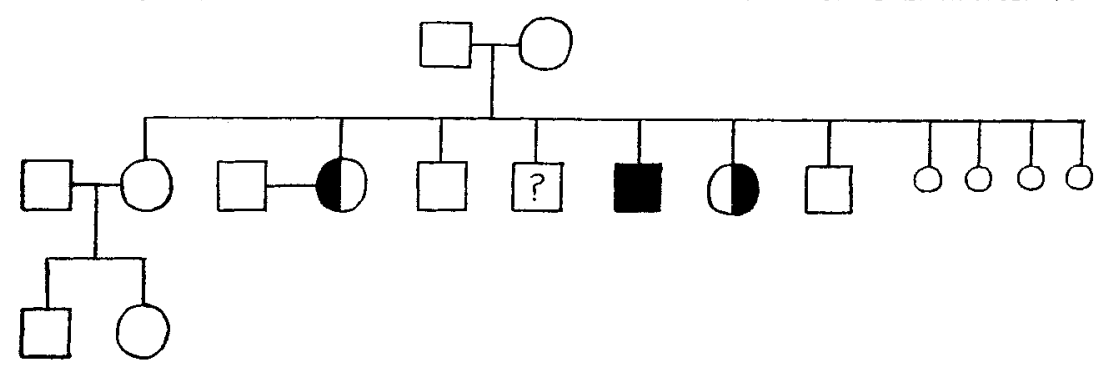

SUMMARY

The paper describes an experiment in studying a well known variation by a new method of approach, that of carrying on the inquiry in the living subject.

A group of one thousand individuals taken at random from dispensary patients in St. Louis constituted the material in which the search for the supracondyloid process was made. The group was composed of whites and colored of both sexes ranging in age from 2 to 75 years. It is a fair sample of the poorer element of the City under medical care.

Record was made of the dispensary numbers of all of the subjects through which their medical histories became available. The method of examination for the variation was palpation of the arms and confirmation of observations by the X-ray. It was found possible to recognize the process form of the variation and its relation to large arteries and nerves by palpation; its position, form and approximate size by the Roentgen ray. The X-ray revealed additional features of interest in connection with the variation. Inquiry carried to members of the subjects' families which is in progress, has brought to light further evidence of the hereditary nature of the supracondyloid pro- 
cess. Body measurements and other anthropological data have beer secured. The possible functional bearing of the process and its possible correlation with mental defect are the subjects of inquiry upor which interesting observations have already been secured.

The reliability of the method was tested by a study of the inc1dence found. In attempting to compare the incidence derived by this method with the figures of previous writers from observations on the cadaver and the skeleton, an apparent great discrepancy was ind1cated. This discrepancy is the result both of non-conformity on the definition of the variation and on the method of computing the inc1dence. When figures which have been derived by similar methods of examination of the same types of process are compared a rather close agreement is found among the percentages that have been giver. This is true for the results of the method used in the present work and its usefulness within certain limits (vide infra) is therefort demonstrated. The incidence of persons having the supracondyloid variation in the form of a process $4-7.2+\mathrm{mm}$. in height was found to be $0.7 \%$. The incidence of these processes in 520 pairs of arms of adult whites was $0.6-\%$. The figure $1 \%$ probably represents the incidence of the spine-formed process (inclueing those of 3-4 $\mathrm{mm}$.) in the humeri of the white race. 


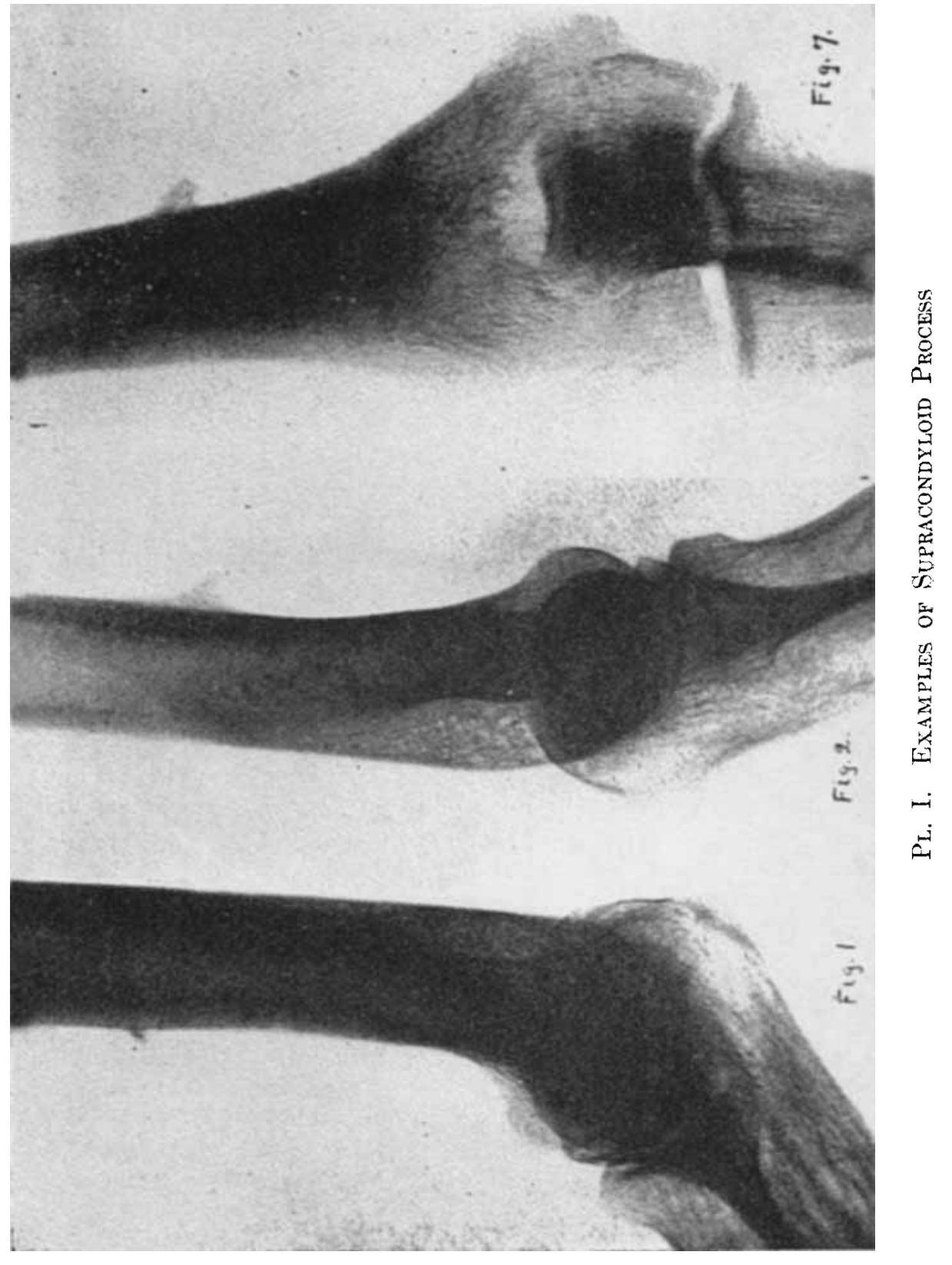




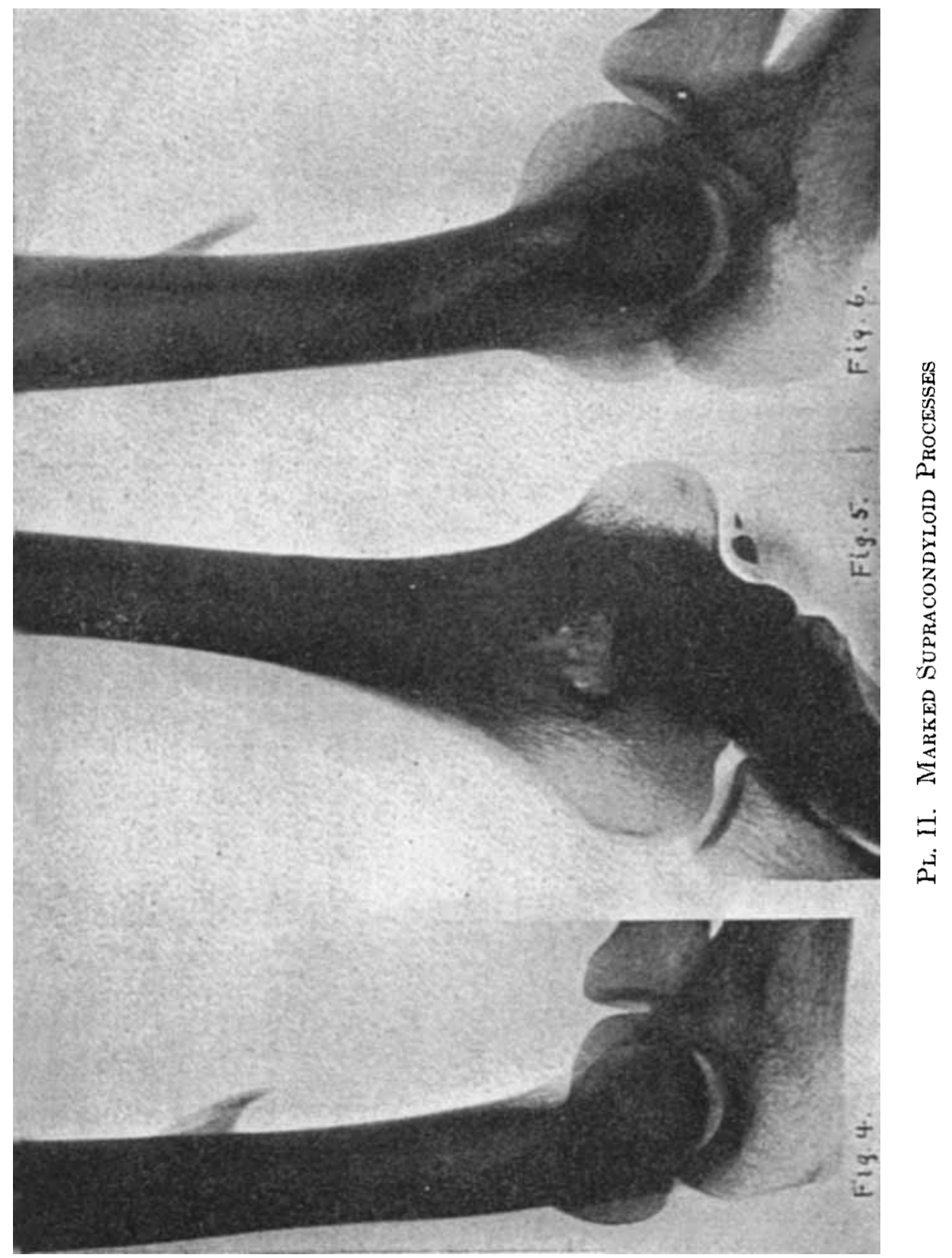




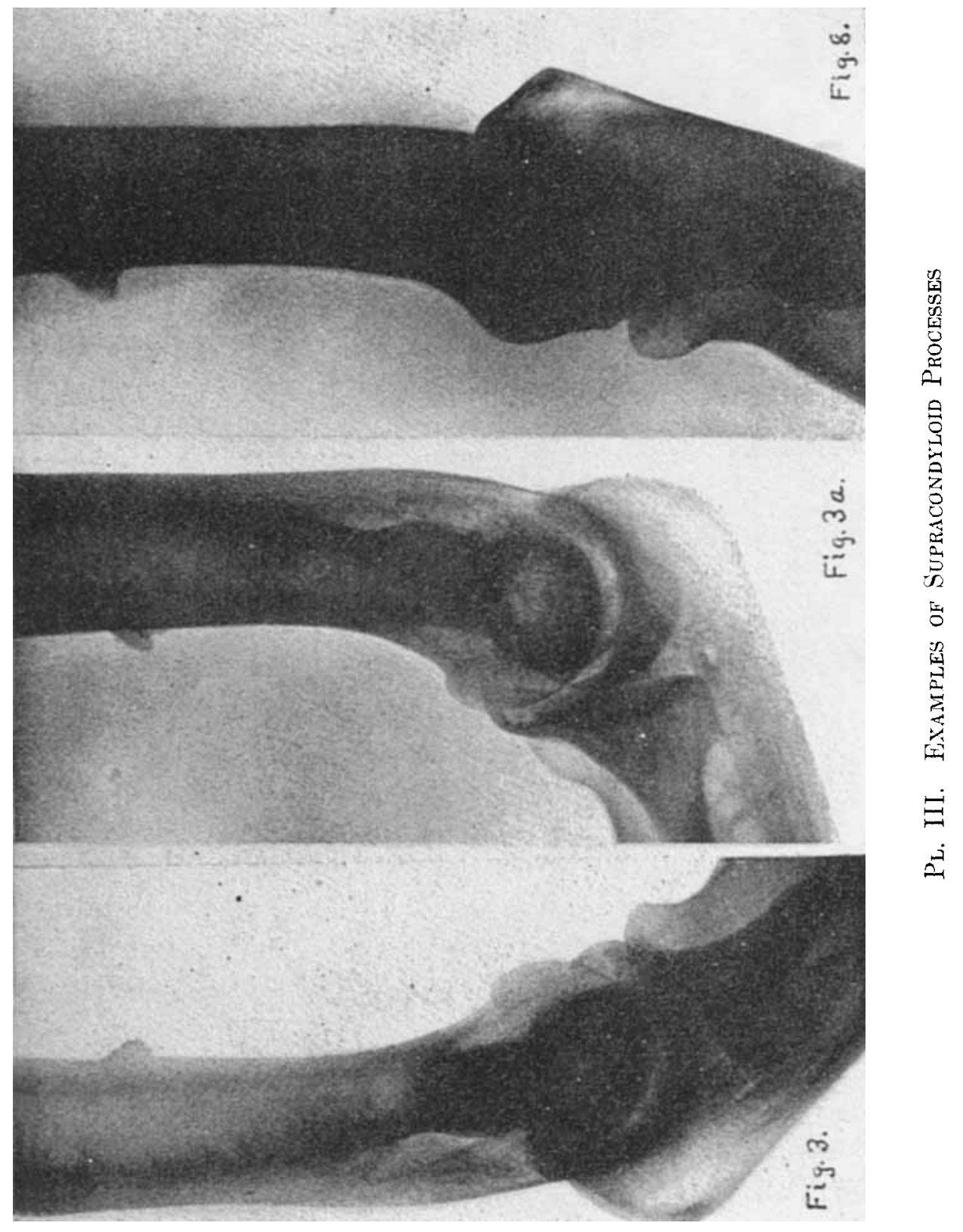

